\title{
IMPLEMENTATION OF LOAD FREQUENCY CONTROL OF SSSC AND CES BASED HYDROTHERMAL SYSTEM UNDER OPEN MARKET SCENARIO EMPLOYING FUZZY LOGIC CONTROLLER
}

\author{
Ponnusamy MARIMUTHU*, Banakara BASAVARAJA*, Sekhar Dash SUBHRANSU** \\ *Department of EEE, Annapoorana Engineering College, Salem, India, e-mail: spm_muthu2001@yahoo.com \\ **Department of EEE, GITHAM University (Hyderabad Campus), Hyderabad, India, e-mail: banakara36@gmail.com \\ ***Department of EEE, SRM University, Chennai, India, e-mail: munu_dash_2k@yahoo.com
}

\begin{abstract}
This paper presents the analysis of Static Synchronous Series Compensator (SSSC) and Capacitive Energy storage (CES) based on hydrothermal system under open market scenario employing fuzzy logic controller. The formulation of Load Frequency Control (LFC) problem has been greatly affected due to open transmission access and evolution of more socialized companies for generation, transmission and distribution. The traditional LFC has been modified by taking into account the concept of bilateral contracts. Attempt has also been made to incorporate the concept of SSSC and CES to further improve the performance of the system. A detailed representation of design of Fuzzy Logic Controller (FLC) has been represented and the results have been compared with those of dual mode controller. The results indeed demonstrate the superior working of FLC than that of dual mode controller and the system shows better response with respect to peak time, overshoot and settling time in the presence of FLC.
\end{abstract}

Keywords: Fuzzy Logic Controller, Static Synchronous series compensator, Capacitive Energy Storage, Hydrothermal System, Open market

\section{INTRODUCTION}

The process of maintaining several sets of balances form the process of successful operation of power system. The two balances which are predominant factors to keep frequency constant are load-generation scheduled and actual tie line flows [1], [2]. A good operation of system is identified by its constant frequency of operation and quality of supplied power to its consumers. This is generally carried out by varying the generation as per the load demand. Generally if frequency is low, then the amount of generation is increased and if the frequency is high, the generation is decreased. One of the most important control functions in the operation of power systems that are interconnected is the Secondary control or load-frequency control. The concept of LFC has been developed to maintain a constant frequency and to regulate the tie line flows. It regulates the frequency deviations and tie line interchanges between different areas that are interconnected with each other. The electric industry at current stage is undergoing change from a form of vertically integrated utility system which provides power at regulated rates to a system that constitutes companies competing with each other to sell power at lower rates. The various entities in such a type of system are generating companies (GENCOs), transmission companies (TRANSCOs) and distribution companies (DISCOs). The fundamental role of LFC in this type of power system structure is to enable exchange of power and to also provide better conditions for trading of power.

The concept of controlling generation in power systems under open market scenario has been presented in [3]. The implementation of independent system operator (ISO) to balance the economics along with efficient working of the system has also been presented in [4], [5]. A detailed review of how the concept of LFC under open market scenario can be simulated and assessed has been presented in [6], [7], [16].
On the other hand, various FACTS devices have been widely employed for the control of power systems which provide better stability to the system in [11], [14]. Static Synchronous series compensator (SSSC) and Capacitive Energy storage (CES) are seen as effective devices to bring about better dynamic response of the system.

The most widely employed controller is the conventional proportional integral (PI) controller. The main advantage of PI controller is that it can reduce the steady state error to zero but generally gives large frequency deviations. The optimal control is quite often impractical for the implementation because it is a function of all the states of the system but in practice, all the states may not be available in [12], [13], [15]. The inaccessible states or missing states are required to be estimated. In variable structure or sliding mode control system the structure of the control law may change (e.g. jump of controller parameter values, change of the form of the function) during the course of action in accordance with the state, output or error measurement in [8], [9], [10].

Most of the work relating to LFC of multi area system under open market scenario does not consider the presence of SSSC and CES to bring about better dynamic performance of the system. Further very little work has been carried out in the implementation of Fuzzy Logic Controller to the above system. The remainder of the paper is organized as follows: Section 2 focuses on the dynamic mathematical model of two-area hydrothermal system. Section 3 deals with the design of FLC and its application to LFC. Section 4 explains the design of dual mode PI controller. Section 5 explains the design of SSSC and CES. Section 6 deals with results and discussions. In Section 7 some conclusions are drawn.

\section{DYNAMIC MATHEMATICAL MODEL}

Electric power systems are generally very complex, nonlinear dynamic systems. The control valves associated 
with high pressure turbine are controlled by the load frequency controller for very small variations. The system under study is multi area hydrothermal system under open market scenario. All the various elements of the system such as governor, turbine and power system are represented by first order transfer function according to
IEEE Committee report [17]. Fig. 1 shows the transfer function block diagram of a two-area interconnected hydrothermal system with SSSC and CES under open market scenario. The parameters of two-area model are defined in Appendix.

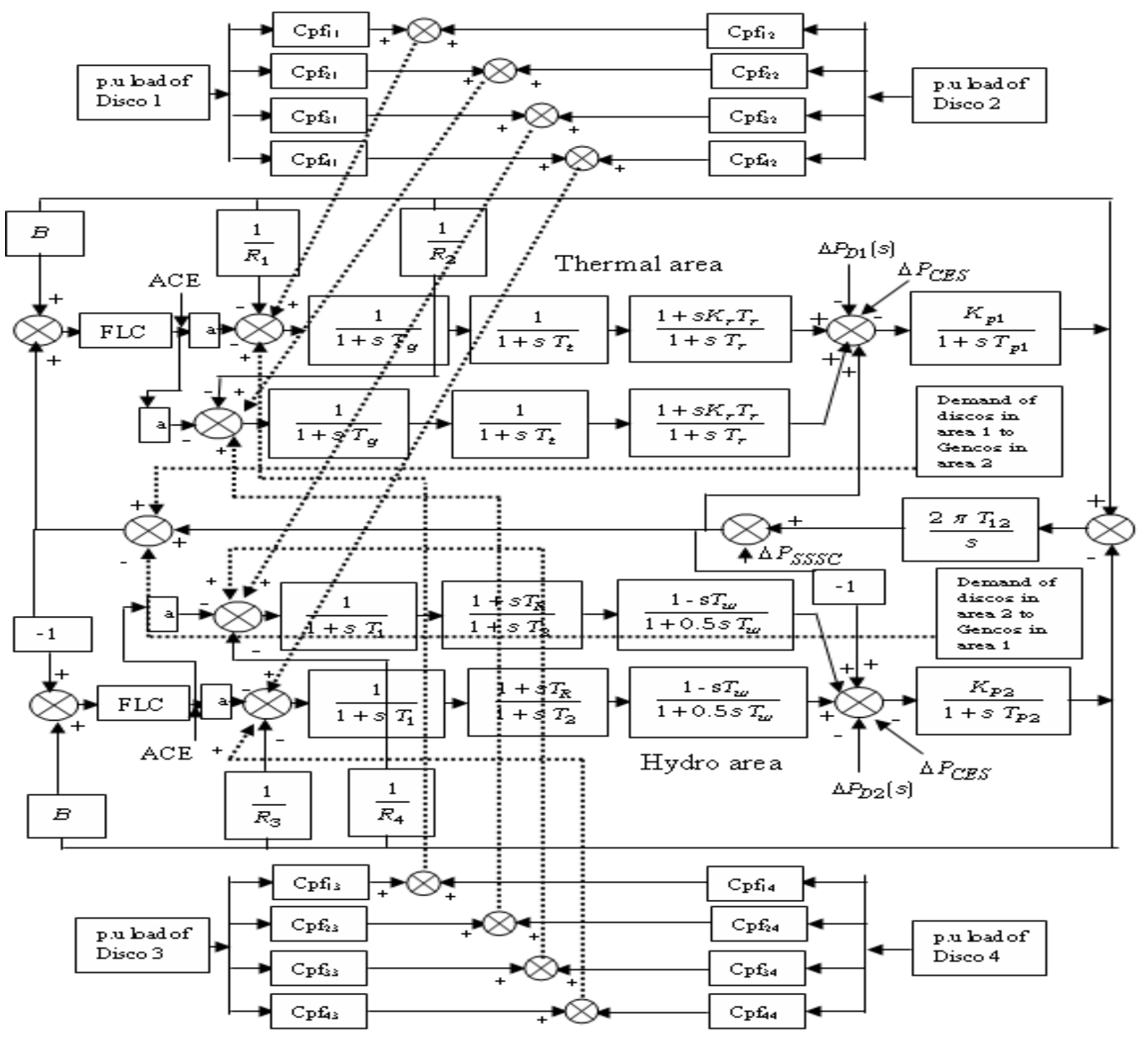

Fig. 1 SSSC and CES based two area hydrothermal systems under open market scenario employing FLC

\section{DESIGN OF FLC}

In this work PI- like Fuzzy Knowledge Based Controller has been designed. The generalized basic structure of the conventional PI controller can be written as

$u=K_{p} e+K_{I} \int e d t$

where $K_{p}$ and $K_{I}$ form the proportional and integral gains respectively and e is the error signal. Performing the derivative with respect to time, Eq.(1) is written into the following equivalent expression

$\dot{u}=K_{p} \dot{e}+K_{I} e$
For the LFC problem, the Area Control Error (ACE) will be considered as the input as a result of which $\operatorname{ACEi}(\mathrm{t})$ and $\triangle \mathrm{ACEi}(\mathrm{t})$ form the inputs to the Fuzzy controller for $i^{\text {th }}$ area at a particular instant time ' $\mathrm{t}$ ', where $\operatorname{ACEi}(\mathrm{t})=\Delta \mathrm{Ptiei}+\mathrm{Bi} \Delta \mathrm{fi}$ and $\Delta \mathrm{ACEi}(\mathrm{t})=\operatorname{ACEi}(\mathrm{t})-$ $\mathrm{ACEi}(\mathrm{t}-1)$ and output of the fuzzy controller is $\Delta \mathrm{u}$ where $\Delta$ Ptiei is the tie line power deviation and $\mathrm{Bi}$ is the bias. This can be seen as is in accordance with the Eq. (2) for PI controller. Seven linguistic variables NB, NM, NS, Z, PS, $\mathrm{PM}$ and $\mathrm{PB}$ which stand for Negative Big, Negative Medium, Negative small, Zero, Positive Small, Positive Medium and Positive Big respectively are considered for transforming the input and output variables. The membership function considered is symmetrical triangular membership function for all the 3 variables ACE, $\triangle \mathrm{ACE}$ and $\Delta$ u. Fig. 2 shows the membership function of ACE 
over the maximum and minimum operating ranges. It can be observed that a mapping would be performed by the membership function to convert crisp value to fuzzified value. It can be observed from the figure that a particular crisp value of ACE can be converted into fuzzified value like $\frac{0.8}{N S}+\frac{0.2}{N M}$ where the values of 0.8 and 0.2 form the membership grades corresponding to variables NS and NM of the system. The membership grades of the remaining linguistic variables become zero. In this way the crisp inputs can be converted into the fuzzified inputs for the remaining values also.

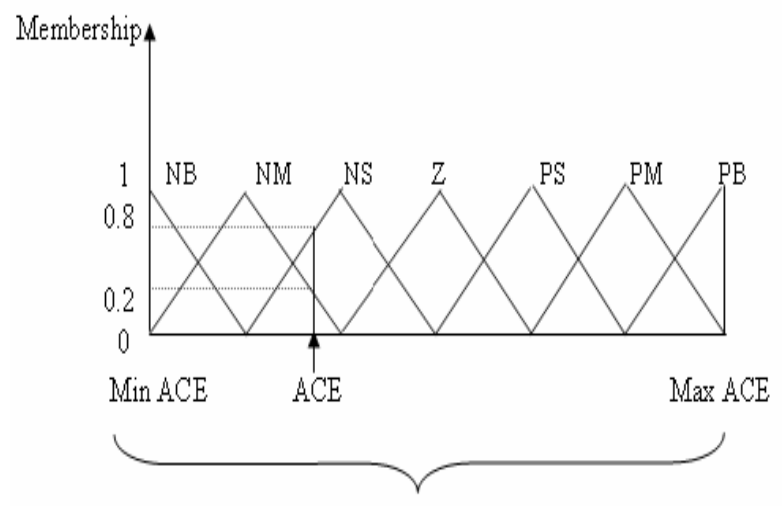

Fig. 2 Membership functions for the fuzzy variable

\section{A. Procedure for Framing the Rules}

In this work, the three fuzzy variables have been quantized to seven fuzzy sets, a result of which $7 \times 7$ or 49 rules have been formulated to generate a fuzzified output. The various fuzzy rules employed to generate a fuzzy output have been shown in Table 1.

Generally the fuzzy rules play a huge part in the design of FLC and have been investigated thoroughly in this work. The fuzzy rules are usually generated employing the knowledge and operational experience of the system or by clearly understanding the dynamics of the system. Depending on the dynamics of the system, the entire rule has been divided into 4 regions like $\mathrm{A}, \mathrm{B}, \mathrm{C}$ and $\mathrm{D}$ as shown in Fig 3. It can be observed form the fig. 3 that if the value of $e$ is positive and $\Delta e$ is negative, then automatically the error is reduced by the system itself, which indicates that the value of control action applied should be zero. It can be viewed in Fig 3 as the region labelled as A. If $e$ is taken to be negative and $\Delta e$ is also considered to be negative, then the system has the tendency to go into instability. At this point a positive control action is required in order to bring the system into stable point. This can be viewed as region $\mathrm{B}$ in the figure. In the case of region $C$, it can be observed that even while the error is still negative, the rate of change of error has been positive. This can be viewed that the error is decreasing and zero control action is to be considered. Whenever the error and rate of change of error are positive, there is every possibility that the region might go into instability region and as a result opposite i.e., negative control action is required to compensate this movement. Mamdani correlation minimum encoding inference has been employed to determine the firing strength of fuzzy control rule.

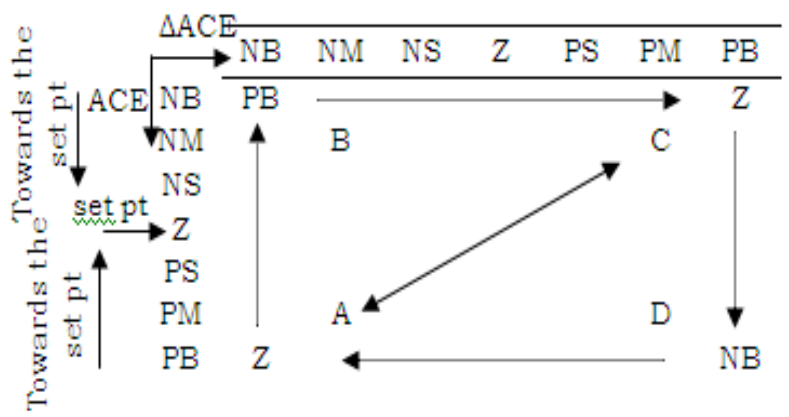

Fig. 3 Rules generation by understanding system dynamics

Table 1 Fuzzy rules for two area system

\begin{tabular}{|c|c|c|c|c|c|c|c|c|}
\hline \multirow{2}{*}{\multicolumn{2}{|c|}{$\stackrel{\Delta \mathrm{ACE}}{\longrightarrow}$}} & \multirow[b]{2}{*}{ NB } & \multirow[b]{2}{*}{ NM } & \multirow[b]{2}{*}{ NS } & \multirow[b]{2}{*}{$Z$} & \multirow[b]{2}{*}{ PS } & \multirow[b]{2}{*}{ PM } & \multirow[b]{2}{*}{ PB } \\
\hline & & & & & & & & \\
\hline \multirow{7}{*}{$\mathrm{ACE} \downarrow$} & NB & PB & PB & PM & PM & PS & PS & $Z$ \\
\hline & NM & PB & $\overline{P M}$ & PM & PS & PS & $Z$ & $Z$ \\
\hline & NS & PM & PS & PS & PS & $Z$ & $Z$ & $Z$ \\
\hline & $Z$ & $Z$ & $Z$ & $Z$ & $Z$ & $Z$ & $Z$ & $Z$ \\
\hline & $\overline{P S}$ & $Z$ & $Z$ & $Z$ & NS & $Z$ & NS & NS \\
\hline & PM & $Z$ & $Z$ & NS & NS & NM & NM & NB \\
\hline & PB & $Z$ & NS & NS & $\mathrm{NM}$ & NM & NB & $\mathrm{NB}$ \\
\hline
\end{tabular}

For example, suppose that at a certain instant $t$, the Fuzzy logic employs a rule: If ACE (t) is NS and $\triangle \mathrm{ACE}$ (t) is NM then control action $\Delta \mathrm{u}$ is PS.

The firing strength of a fuzzy control rule will be

$$
\begin{aligned}
& \mu_{A \cap B}(A C E(t), \triangle A C E(t))=\min \left(\mu_{A C E}(A C E(t),\right. \\
& \mu_{\triangle A C E}(\triangle A C E(t))
\end{aligned}
$$

where, A:'NS', B: 'NM', $\mu_{A C E}$ and $\mu_{\triangle A C E}$ represent the membership functions of the linguistic values of error and rate of change of error. Suppose, e belongs to NS with a membership of 0.3 and $\Delta \mathrm{e}$ belongs to NM with a membership of 0.7 , then the rule consequence $\left(\mathrm{w}_{\mathrm{i}}\right)$ will be 0.3 , the minimum between 0.3 and 0.7 .

\section{B. Defuzzification}

The conversion of fuzzified outputs into the crisp outputs can be seen as the process of defuzzification. Generally the output of a fuzzy controller will be a fuzzified value, as a result of which it will be necessary to convert this value into crsip value. The center of gravity defuzzification method has been employed in this work due to its simplicity. The control output $\Delta u$ is determined using the center of gravity by the following expression,

$$
\Delta u=\frac{\sum \text { membership of input } \times \text { output correspondings }}{\sum \text { membership of input }}
$$




$$
\Delta u=\frac{\sum_{j=1}^{49} \mu_{j} u_{j}}{\sum_{j=1}^{49} \mu_{j}}
$$

where, $\mu_{j}$ is the membership value of the linguistic variable recommending the fuzzy controller action, and $u_{j}$ is the precise numerical value corresponding to that fuzzy controller action. This $\Delta \mathrm{u}$ when added with the previous signal will be the actual signal fed to the governor. The schematic representation of FLC applied to the system can be represented in Fig 4.

\section{DUAL MODE CONTROLLER}

The steady state error of the system can be brought to zero employing the integral controller but it results in high overshoot and settling time. Generally the overshoot can be reduced employing the proportional controller. So effort has been made in this work, to develop a dual mode controller which employs both integral controller and proportional controller.

Depending on the magnitude of the error signal i.e., $A C E(t)$ the control law can be switched between the discontinuous mode or the continuous mode. If $|A C E(t)|>\varepsilon$ the output of the controller is

$\Delta P_{c}(t)=-K_{p} \cdot A C E(t)$

where

$\Delta P_{c}(t)=$ output signal of the controller

$\varepsilon=$ constant indicating the specified limit of error signal $K_{p}=$ proportional controller

And, for $|A C E(t)|<\varepsilon$

$\Delta P_{c}(t)=-K_{i} \int A C E(t) d t$

Depending on the above concept it can be depicted in Fig. 5 as follows:

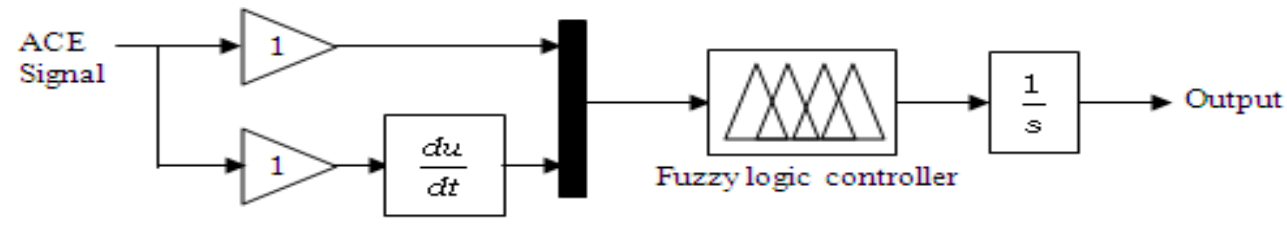

Fig. 4 Schematic diagram of FLC employed

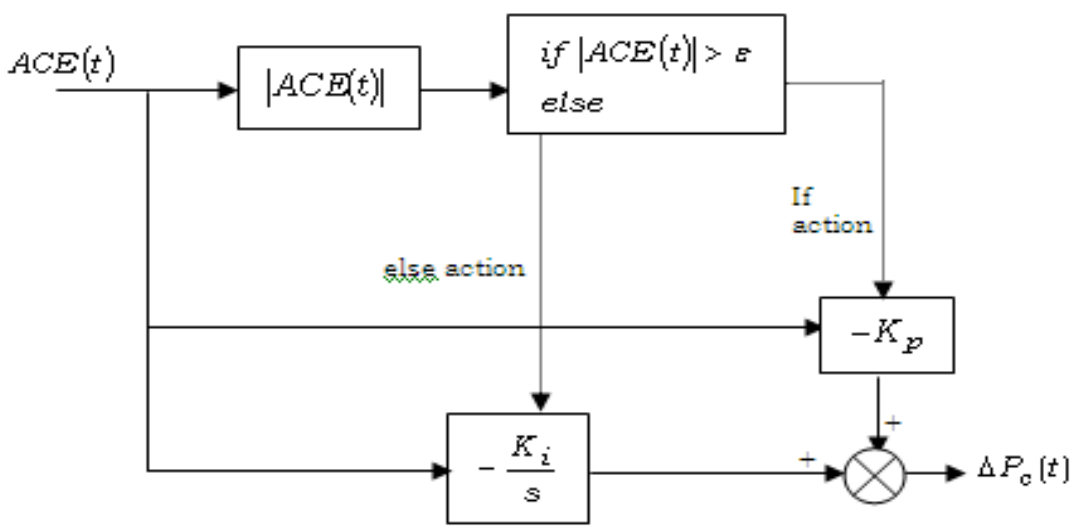

Fig. 5 Schematic diagram of Dual mode controller employed

\section{MODELING OF SSSC AND CES}

\subsection{Design of SSSC}

Fig 6 shows the schematic diagram of SSSC located in series with the tie line between the interconnected areas. Generally the equivalent circuit is represented by a series connected voltage source $V_{S}$ along with a transformer leakage reactance $X_{s}$ as shown in Fig 7. The main controllable parameter is $V_{s}$, which in fact represents the magnitude of injected voltage. The phasor diagram of system is shown in Fig. 8 by taking into account the operating conditions of SSSC.
Based on the above figure when $V_{S}=0$, the current $I_{o}$ of the system can be written as

$$
I_{o}=\frac{V_{m}-V_{n}}{j X_{T}}
$$

where $X_{T}=X_{L}+X_{S}$. The phase angle of the current can be expressed as:

$\theta_{c}=\tan ^{-1}\left[\frac{V_{n} \cos \theta_{n}-V_{m} \cos \theta_{m}}{V_{m} \sin \theta_{m}-V_{n} \sin \theta_{n}}\right]$ 
But Eq. (6) can be expressed in a generalized form as: $\quad I=\frac{V_{m}-V_{s}-V_{n}}{j X_{T}}=\left[\frac{V_{m}-V_{n}}{j X_{T}}\right]+\left[\frac{-V_{s}}{j X_{T}}\right]=I_{o}+\Delta I$

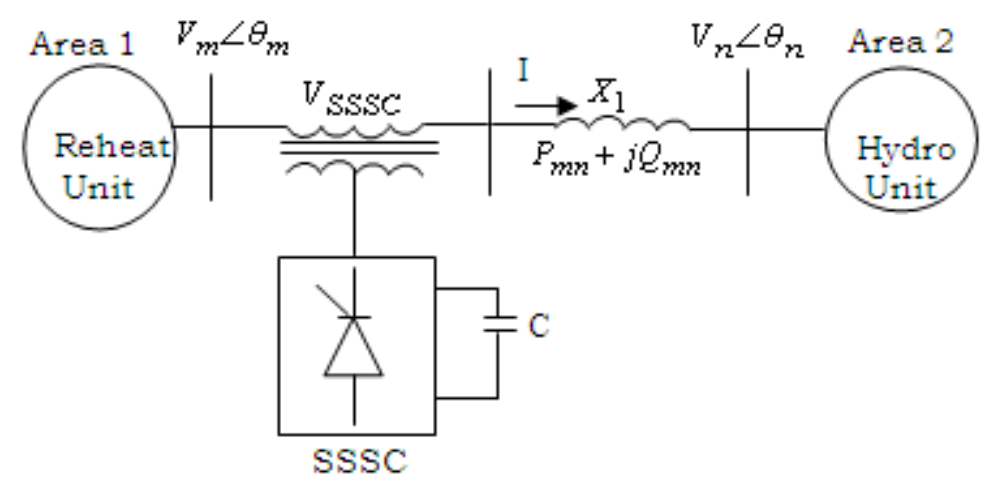

Fig. 6 Schematic of SSSC applied to two - area interconnected system

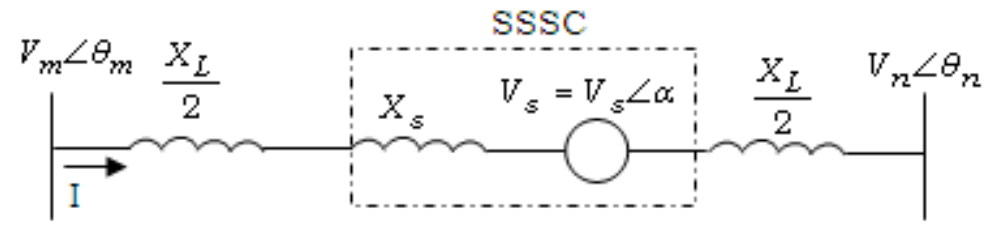

Fig. 7 Equivalent circuit of SSSC
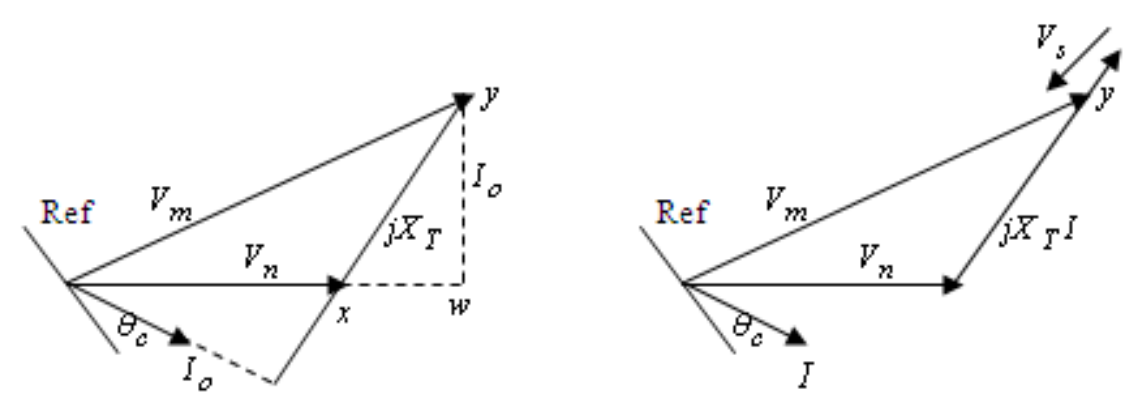

Fig. 8 Phasor diagram at (a) $V_{\mathrm{s}}=0$; (b) $\mathrm{V}_{\mathrm{s}}$ lagging I by $90^{\circ}$

The term $\Delta I$ is an additional current term due to SSSC voltage $V_{s}$. The power flow from bus $m$ to bus $n$ can be written as $S_{m n}=V_{m} I^{*}=S_{m n o}+\Delta S_{m n}$ which implies

$$
P_{m n}+j Q_{m n}=\left(P_{m n o}+\Delta P_{m n}\right)+j\left(Q_{m n o}+\Delta Q_{m n}\right)
$$

where $P_{m n o}$ and $Q_{m n o}$ are the real and reactive power flow respectively when $V_{S}=0$. The change in real power flow caused by SSSC voltage is given by:

$$
\Delta P_{m n}=\frac{V_{m} V_{s}}{X_{T}} \sin \left(\theta_{m}-\alpha\right)
$$

When $V_{s}$ lags the current by $90^{\circ}, \Delta P_{m n}$ can be written as:

$$
\Delta P_{m n}=\frac{V_{m} V_{s}}{X_{T}} \cos \left(\theta_{m}-\theta_{c}\right)
$$

From Eq (7) the term $\cos \left(\theta_{m}-\theta_{c}\right)$ can be written as:

$\cos \left(\theta_{m}-\theta_{c}\right)=\frac{V_{n}}{V_{m}} \cos \left(\theta_{n}-\theta_{c}\right)$

Referring to Fig. 6 it can be written as

$\cos \left(\theta_{n}-\theta_{c}\right)=\frac{y w}{x y}$

and it can be seen as:

$y w=V_{m} \sin \theta_{m n}$

Also $x y=\sqrt{V_{m}^{2}+V_{n}^{2}-2 V_{m} V_{n} \cos \theta_{m n}}$ and

$\theta_{m n}=\theta_{m}-\theta_{n}$

Using these relationships Eq. (11) can be modified as follows 


$$
\Delta P_{m n}=\frac{V_{m} V_{n}}{X_{T}} \sin \theta_{m n} \times \frac{V_{s}}{\sqrt{V_{m}^{2}+V_{n}^{2}-2 V_{m} V_{n} \cos \theta_{m n}}}
$$

From Eq. (9) it can be written as $P_{m n}=P_{m n o}+\Delta P_{m n}$ which implies

$$
\begin{aligned}
& P_{m n}=\frac{V_{m} V_{n}}{X_{T}} \sin \theta_{m n}+\left(\frac{V_{m} V_{n}}{X_{T}} \sin \theta_{m n} \times\right. \\
& \left.\frac{V_{s}}{\sqrt{V_{m}^{2}+V_{n}^{2}-2 V_{m} V_{n} \cos \theta_{m n}}}\right)
\end{aligned}
$$

Linearizing Eq. (17) about an operating point it can be written as

$$
\begin{aligned}
& \Delta P_{m n}=\frac{V_{m} V_{n}}{X_{T}} \cos \left(\theta_{m}-\theta_{n}\right)\left(\Delta \theta_{m}-\Delta \theta_{n}\right)+ \\
& \left(\frac{V_{m} V_{n}}{X_{T}} \sin \theta_{m n} \times \frac{\Delta V_{s}}{\sqrt{V_{m}^{2}+V_{n}^{2}-2 V_{m} V_{n} \cos \theta_{m n}}}\right)
\end{aligned}
$$

$$
\begin{aligned}
& \Delta P_{m n}=\Delta P_{t i e}+\Delta P_{S S S C} \text { which implies } \\
& \Delta P_{S S S C}=\left(\frac{V_{m} V_{n}}{X_{T}} \sin \theta_{m n} \times \frac{\Delta V_{s}}{\sqrt{V_{m}^{2}+V_{n}^{2}-2 V_{m} V_{n} \cos \theta_{m n}}}\right)
\end{aligned}
$$

Based on Eq. (19) it can be observed that the power output of SSSC can be controlled by varying the SSSC voltage $\Delta V_{S}$ and thus the frequency and tie line deviations can be controlled. Fig. 9 shows the structure of SSSC to be incorporated along the hydrothermal system. It can be seen from Fig. 9 that the structure of SSSC consists of gain block $K_{S S S C}$, time constant $T_{S S S C}$ and two stage phase compensation blocks having time constants $T_{1}, T_{2}, T_{3}, T_{4}$ respectively.

\subsection{Design of CES}

The frequency deviation or Area control error signal can be employed as the control signal for the CES unit. Fig. 10 shows the block diagram representation of CES unit employed in the system.

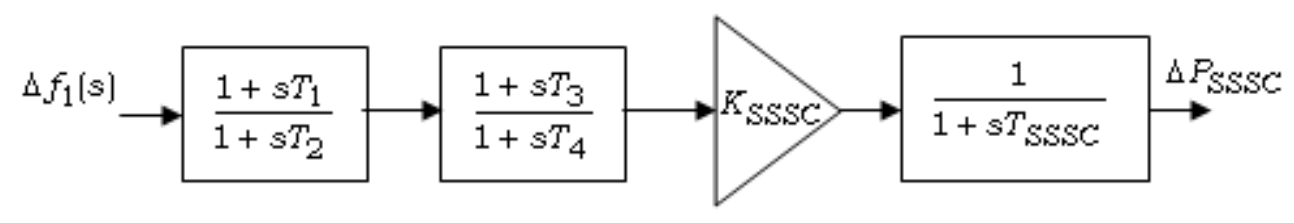

Fig. 9 Structure of SSSC

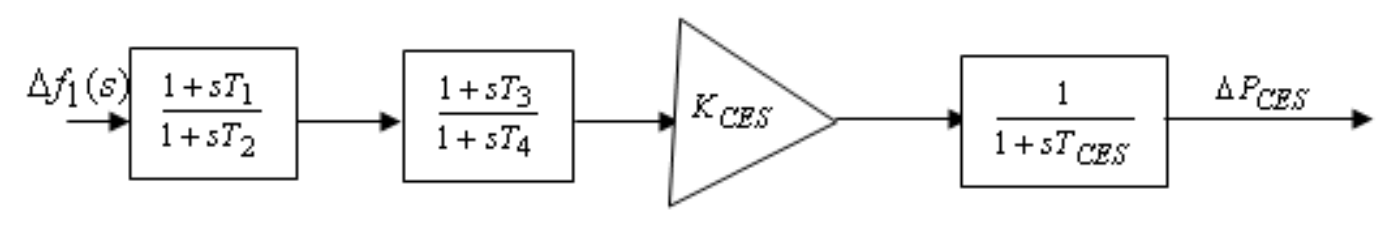

Fig. 10 Schematic diagram of CES applied to LFC

\section{RESULTS AND DISCUSSIONS}

A multi area SSSC and CES based hydrothermal system under open market scenario has been considered for the study. It is to be noted that each Genco participates in LFC as per the following area participation factors (apf): apf1 $=0.5$, apf2 $=0.25$, apf3 $=0.25$, apf4 $=0.5$, apf5 $=0.25$, apf6 $=0.25$. A step load disturbance of $0.4 \%$ is considered in either of the areas. A special case of contract violation has also been considered in which an additional load of $0.3 \%$ - is considered in both the areas after the time span of $35 \mathrm{~s}$ and $70 \mathrm{~s}$. It is to be noted that this additional load is taken up by the Gencos which lie in the area in which contract violation has occurred. The Disco Participation Matrix Considered in this work is given by

$$
\left[\begin{array}{llll}
0.1 & 0.0 & 0.3 & 0.4 \\
0.0 & 0.1 & 0.0 & 0.2 \\
0.3 & 0.4 & 0.1 & 0.0 \\
0.2 & 0.0 & 0.2 & 0.1 \\
0.2 & 0.3 & 0.0 & 0.1 \\
0.2 & 0.2 & 0.4 & 0.2
\end{array}\right]
$$

Table 2 shows the comparison between the performance of SSSC and CES based hydrothermal system in the presence of fuzzy logic controller and dual mode controller. It can be observed that the fuzzy logic controller gives better performance than that of dual mode controller. Table 3 shows the comparison between the two controllers in terms of performance index. It can also be observed for the table that the system with FLC has less value of performance index. Figs. 11-13 show the 
comparison of fuzzy logic controller and dual mode controller with $0.4 \%$ load disturbance in each area. Figs. 14-16 show the performance of fuzzy logic controller and dual mode controller in the case of contract violation. Fig. 17 compares the performance index value of FLC and dual mode controller. It can be seen the FLC has least performance index value which indicates the superior performance of fuzzy logic controller over other controller.

Table 2 Comparison of performance of system with fuzzy logic controller

\begin{tabular}{|c|c|c|c|c|c|c|}
\hline & \multicolumn{3}{|c|}{ Thermal Area } & \multicolumn{3}{c|}{ Hydro Area } \\
\hline & $\begin{array}{c}\text { Peak } \\
\text { Time } \\
(\mathrm{sec})\end{array}$ & $\begin{array}{c}\text { Overshoot } \\
(\mathrm{Hz})\end{array}$ & $\begin{array}{c}\text { Settling } \\
\text { Time } \\
(\mathrm{sec})\end{array}$ & $\begin{array}{c}\text { Peak } \\
\text { Time } \\
(\mathrm{sec})\end{array}$ & $\begin{array}{c}\text { Overshoot } \\
(\mathrm{Hz})\end{array}$ & $\begin{array}{c}\text { Settling } \\
\text { Time (sec) }\end{array}$ \\
\cline { 2 - 7 } & 2.21 & 0.00283041 & 7.54 & 0.83 & 0.00583378 & 4.24 \\
$\begin{array}{c}\text { With dual mode } \\
\text { controller }\end{array}$ & 2.17 & 0.00288862 & 3.78 & 0.8 & 0.00554987 & 2.455 \\
\hline $\begin{array}{c}\text { With fuzzy logic } \\
\text { controller }\end{array}$ & & & & & & \\
\hline
\end{tabular}

Table 3 Comparison of Performance Index Values

\begin{tabular}{|c|c|}
\hline & $\begin{array}{c}\text { Performance Index } \\
\text { Value }\end{array}$ \\
\hline $\begin{array}{c}\text { With dual } \\
\text { mode controller }\end{array}$ & $2.593 \times 10^{-5}$ \\
\hline $\begin{array}{c}\text { With fuzzy } \\
\text { logic controller }\end{array}$ & $1.415 \times 10^{-5}$ \\
\hline
\end{tabular}
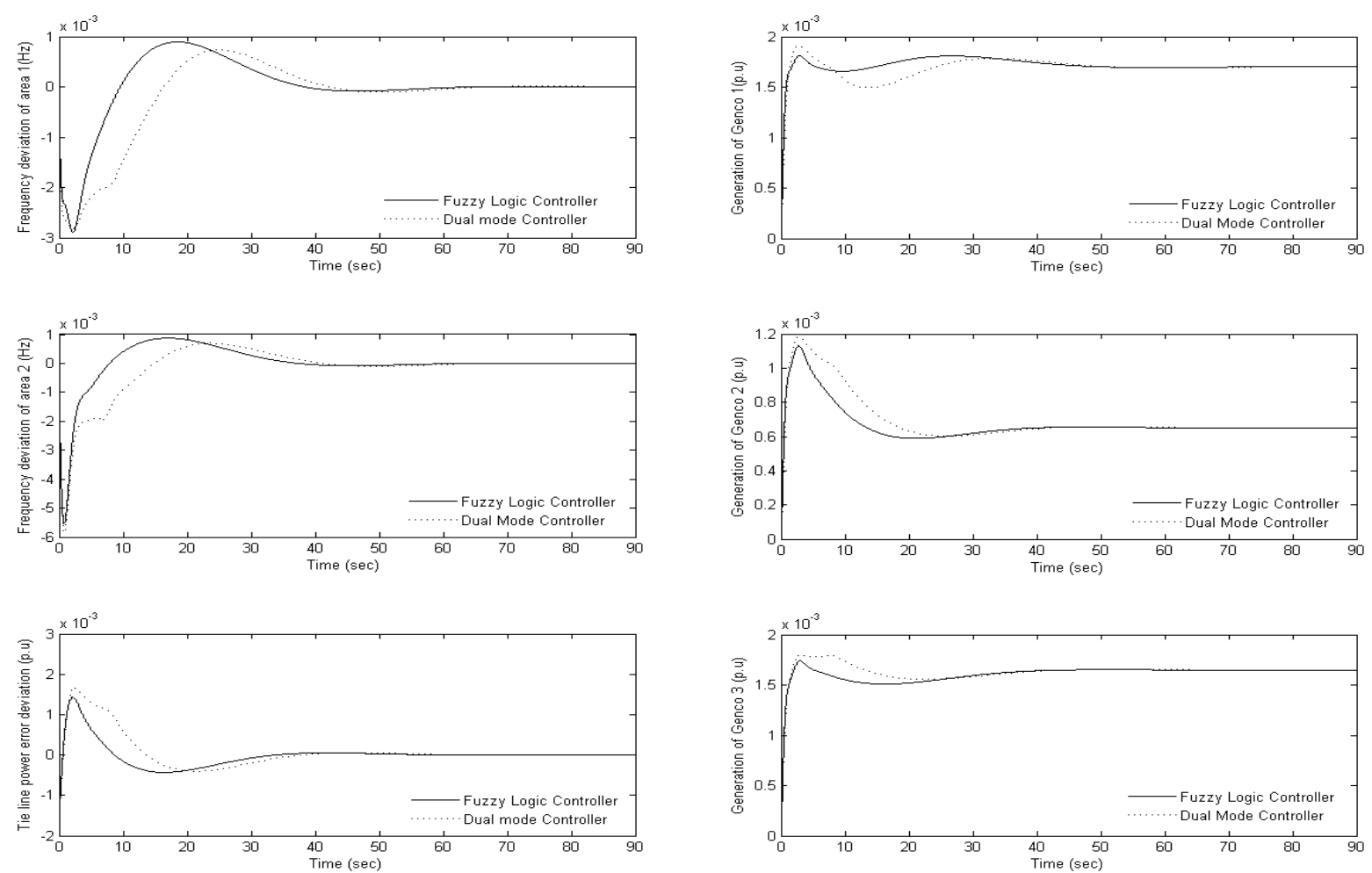

Fig 11 Frequency and tie line power deviations during normal case

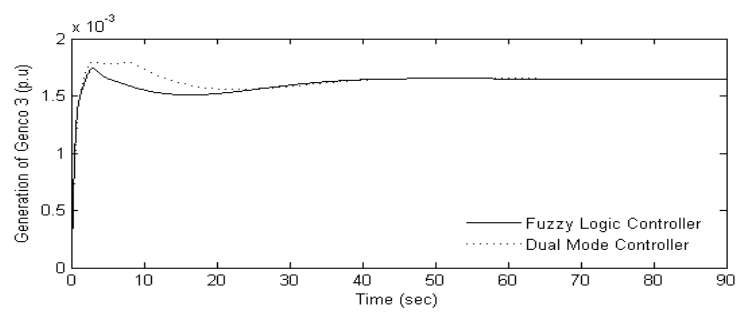

Fig 12 Generation of Gencos of Thermal area 

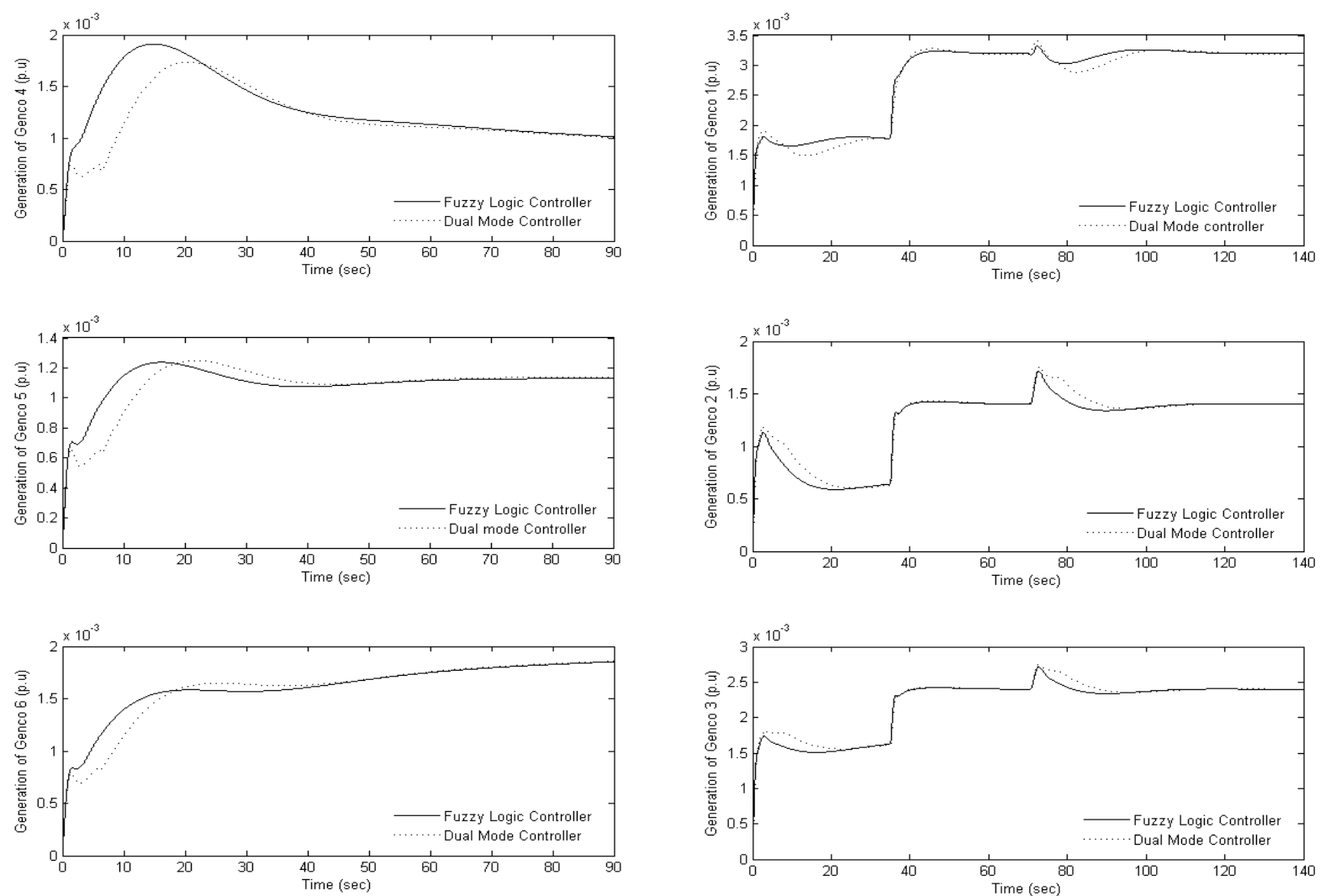

Fig 13 Generation of Gencos of Hydro area

Fig 15 Generation of Gencos of Thermal area
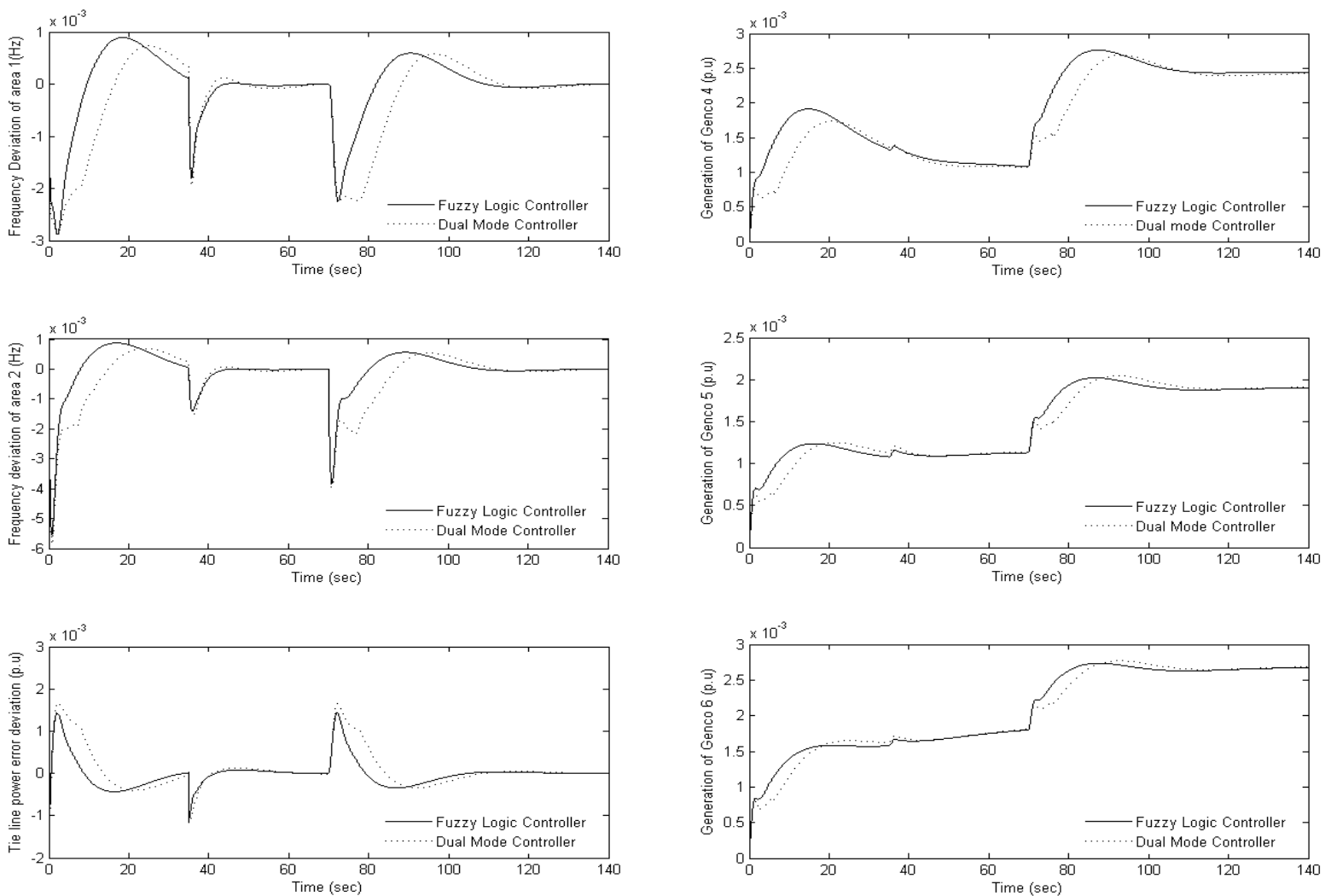

Fig 14 Frequency and tie line power deviations during contract violation case

Fig 16 Generation of Gencos of Hydro area 


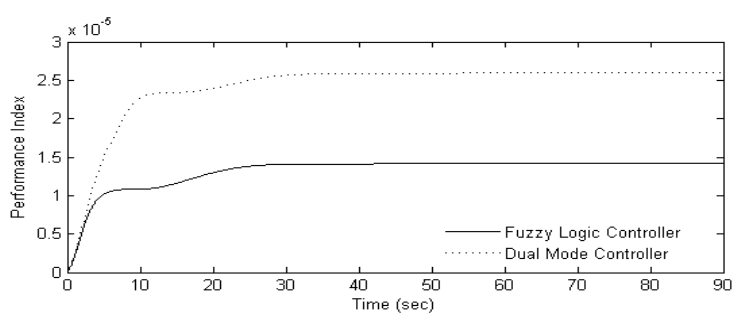

Fig 17 Comparison of Performance Index values between controllers

\section{CONCLUSION}

This paper has investigated the performance of fuzzy logic based controller on a two-area SSSC and CES based hydrothermal system under open market scenario. It is to be noted that generally the conventional design approach involves a deep understanding of the system, exact mathematical models, and precise numerical values whereas the basic feature of the fuzzy logic controller is that with the slight knowledge of the system and with the help of control action, the process can be controlled. A fuzzy rule base with the use of the area control error and rate of change of the error of the system has been built in this work. The simulation results show that the proposed fuzzy logic based controller yields improved control performance than the dual mode controller.

\section{APPENDIX}

(a) System data:

$T_{p 1}, T_{p 2}=20 \mathrm{~s} ; K_{p 1}, K_{p 2}=120 \mathrm{~Hz} /$ p.u.Mw;

$P_{r 1}, P_{r 2}=1200 \mathrm{Mw} ; T_{t}=0.3 \mathrm{~s} ; T_{g}=0.08 \mathrm{~s}, T_{w}=1 \mathrm{~s} ;$

$T_{r}=5 \mathrm{~s}, T_{1}=41.6 \mathrm{~s}, T_{2}=0.513 \mathrm{~s} ; R_{1}, R_{2}=2.4 \mathrm{~Hz} / \mathrm{pu} \mathrm{Mw} ;$

$T_{12}=0.0866 \mathrm{~s} ; B_{1}, B_{2}=0.4249$ p.u Mw/Hz;

(b) CES data:

$T_{1}=0.279 ; T_{2}=0.026 ; T_{3}=0.411 ; T_{4}=0.1 ; K_{C E S}=0.3 ;$

$T_{\text {CES }}=0.0352$

(c) SSSC data:

$T_{1}=0.188 ; T_{2}=0.039 ; T_{3}=0.542 ; T_{4}=0.14 ;$

$K_{\text {SSC }}=0.292 ; T_{\text {SSSC }}=0.030$

\section{REFERENCES}

[1] CONCORDIA, C. - KIRCHMAYER, L. K.: TieLine Power and Frequency Control of Electric Power System - Part II, AIEE Transaction, vol. 73, Part-111-A, pp. 133-146, Apr. 1954.

[2] KOTHARI, M. L. - KAUL, B. L. - NANDA, J.: Automatic Generation Control of Hydro-Thermal system, journal of Institute of Engineers (India), vo1. 61, pt EL2, pp. 85-91, Oct. 1980.
[3] SCHULTE, R. P.: Automatic generation Control modification for present demands on interconnected power systems, IEEE Trans. On Power Systems, pp. 1286-1291, Aug. 1996.

[4] KUMAR, J. - KOENG, K. - SHEBlE, G.: AGC simulator for price based operation Part1, IEEE Transactions on Power Systems, vol. 12, no. 2, pp. 527-532, May 1997.

[5] KUMAR, J. - KOENG, K. - SHEBLE, G.: AGC simulator for price based operation part- 2, IEEE Transactions on Power Systems, vol. 12, no. 2, pp. 533-538, May1997.

[6] BAKKEN, B. H. - OVESGRANDE: Automatic generation control in a deregulated environment, IEEE Transactions on Power Systems, vol. 13, no. 4, pp. 1401-1406, Nov. 1998.

[7] DONDE, V. - PAI, M. A. - HISKENS, I. A.: Simulation of bilateral contracts in an AGC system after restructuring, Power systems engineering research center, Oct. 2000.

[8] CHOWN, G. A. - HARTMAN, R. C.: Design and experience with a fuzzy logic controller for Automatic generation control, IEEETransactions on power systems vol. 13, No. 3, pp. 965-970, Aug. 1998.

[9] NANDA, J. - SAKKARAM, J. S.: Automatic generation control with fuzzy logic controller considering generation rate constraint, Proceedings of $6^{\text {th }}$ International conference on advances in power system control, operation and management, APSCOM-2003, pp. 770-775, Nov. 2003.

[10] NANDA, J. -MANGLA, A.: Automatic generation control of an interconnected hydro-thermal system using conventional integral and fuzzy logic controller, 2004 IEEE conference on Electric utility deregulation, restructuring and power technologies (DRPT 2004), pp. 372-377, Apr. 2004.

[11] ABRAHAM, R. J. - DAS, D. - PATRA, A.: Effect of TCPS on oscillations in tie-power and area frequencies in an interconnected hydrothermal power system, IET Gener. Transm. Distrib, vol. 1, No. 4, pp. 632-639, 2007.

[12] NANDA, J. - PARIDA, M. - KALAM, A.: Automatic generation control of a multi area power system with conventional integral controllers, Proceedings of 2006 Australian University Power engineering conference (AUPEC-06), Dec. 2006.

[13] NANDA, J. - MANGLA, A. - SURI, S.: Some new findings on automatic generation control of an interconnected hydrothermal system with conventional controllers, IEEE Trans. On Energy conversion, vol. 21, No. 1, pp. 187-194, Mar. 2006.

[14] BHATT, P. - GHOSHAL, S. P. - ROY, R.: Optimized Automatic Generation Control by SSSC and TCPS in Coordination with SMES for Two-Area Hydro-hydro Power System, Proceedings of the 2009 International Conference on Advances in 
Computing, Control, and Telecommunication Technologies, pp. 474-480, 2009.

[15] CHATTERJEE, K.: Design of Dual Mode PI Controller for Load Frequency Control, International Journal of Emerging Electric Power Systems, vol. 11 , Issue 4 , article 3 .

[16] DHANALAKSHMI, S. - KANNAN, S. MAHADEVAN, S.: Market modes for deregulated environment - A review, Proceedings of 2011 International conference on Emerging Trends in Electrical and Computer Technology (ICETECT), 23-24 March 2011.

[17] Dynamic Models for steam and Hydro Turbines in Power system studies IEEE committee report. Transactions in Power Apparatus \&Systems, vol. 92, No. 6, pp. 1904-915, Nov./Dec. 1973.

Received August 12, 2013, accepted February 3, 2014

\section{BIOGRAPHIES}

Ponnusamy Marimuthu was born in 1977. He received his B.E. in Electrical and Electronics Engineering from Madras University, India in 1998, his M.E. in Power Systems from Anna University, Chennai, India in 2005. $\mathrm{He}$ is currently working towards his Ph.D. in the field of Improvement of Dynamic performance of Multi Area
Hydro Thermal System at Jawaharlal Nehru Technological University (JNTU), Hyderabad, India. He is a member of the faculty in the Department of Electrical and Electronics Engineering, Annapoorana Engineering College, Salem, India. His research interest includes dynamic response of hydro thermal system, optimal location and Power flow control with FACTS devices.

Banakara Bsavaraja was born in 1970. He is IEEE Member since 2005. He obtained his B.Tech (EEE) degree from Gulbarga University, India, M.Tech from Karantaka University, India and PhD from NIT Warangal, India. He is presently working as a Vice-Principal and Head EEE in GITHAM University (Hyderabad Campus), Hyderabad, India. His area of interest includes power electronics and drives, High voltage Engineering and EMTP applications.

Sekhar Dash Subhransu received the M.E degree in Electrical Engineering from UCE Burla, Orissa, India and Ph.D degree in Electrical Engineering from Anna University in 1996 and 2006 respectively. He is presently working as Professor and Head of the department of Electrical Engineering in SRM University Chennai, India. His area of interest includes Power Quality, Inverters, Multilevel Inverters, Power System Operation, Control \& Stability and Intelligent controlling Techniques. 